\title{
Şanlıurfa İli Suruç İlçesi Topraklarının Bazı Özellikleri ve Bitki Besin Elementi Kapsamlarının Belirlenmesi
}

\author{
Ali Rıza ÖZTÜRKMEN*, Emrah RAMAZANOĞLU, İsmail Cihan ÇİÇEK \\ Harran Üniversitesi Ziraat Fakültesi, Toprak Bilimi ve Bitki Besleme Bölümü, Şanlıurfa \\ (ORCID: 0000-0001-5575-3278) (ORCID: 0000-0002-7921-5703) (ORCID:0000-0003-1534-0466)
}

\begin{abstract}
$\ddot{O} z$
Bu çalışma Şanlıurfa İli Suruç İlçesi topraklarının özellikleri ve toprak verimlilik durumlarının değerlendirilmesi amacıyla yapılmıştır. Suruç Ovası geniş tarım arazilerinin olduğu ve yoğun tarım yapılan Şanlıurfa İlinde yer alan ovalardan biridir. Suruç Ovasından 70 adet toprak örneği 0 - 30 derinlikten GPS ile koordinatları kaydedilerek alınmıştır. Toprak örneklerinde yapılan analizler sonucunda oluşan frekans tablolarına göre; toprakların \%70'i hafif alkalin reaksiyonlu, \%100'ü tuzsuz, \%51'inde organik madde az ve \%65'inin yüksek kireç içerdiği belirlenmiştir. Bitkiye yarayışlı fosforun \%40'ının az, potasyumun \%99'unun yüksek olduğu mikro besin elementlerinden bakırın \%100 yeterli, çinkonun \%67'sinin düşük, demirin \%77'nin düşük ve manganın \%100 yeterli olduğu belirlenmiştir. Suruç ovası toprakları kireçli ana materyal üzerinde oluşan topraklar olduğu için bitkiye yarayışlı fosfor, demir ve çinko açısından sorun oluşturmaktadır.
\end{abstract}

Anahtar kelimeler: Suruç Ovası, bitki besin elementleri, toprak, toprak verimliliği.

\section{Determination of Some Properties and Plant Nutrient Content of the Soil of Suruç District of Şanlıurfa Province}

\begin{abstract}
This study was carried out to evaluate the soil characteristics and soil fertility conditions of Suruç district of Şanlıurfa Province. Suruç Plain is one of the plains in Şanlıurfa, where there are large agricultural lands and intensive agriculture. 70 soil samples were taken from the $0-30 \mathrm{~cm}$ depths from Suruç Plain by recording their coordinates with GPS. As a result of the analysis on soil samples; It was determined that the soils were slightly alkaline reaction $\% 70$, unsalted $\% 100$, low in organic matter $\% 51$ and very high lime $\% 65$. It is determined that among the micro nutrients that have low phosphorus $\% 40$ and potassium \%99 useful for the plant, \%100 copper is sufficient, \%67 zinc is low, \%77 iron is low and manganese \%100 is sufficient. Since the Suruç Plain is the soil formed on the calcareous main material, it is a problem in terms of beneficial phosphorus, iron and zinc.
\end{abstract}

Keywords: Suruc Plain, plant nutrients, soil, soil fertility.

\section{Giriş}

Toprak genel olarak canlılar için gıda teminini sağlayan bitkisel üretimin yoğun olarak yapıldı̆̆ı, yeryüzünde yaşayan bütün canlılar için barınma ve yaşamını ikame ettiği doğal bir ortamdır [1]. Nüfus artışındaki hız ile birlikte arazi kullanımındaki değişimi de kaçınılmaz bir durum olarak karşımıza çıkmış olup bu durum profesyonelce planlama yapılmadığında büyük ekonomik sorunlara neden olmaktadır [2]. Mevcut tarım arazilerinin verimlilik durumlarının tespiti ve toprak kalitesinin yükseltilmesi yeryüzünde yaşayan canlılar için önemli olup, sürdürülebilir tarımsal üretim içinse toprakların yönetilmesi ise zorunlu bir durum olmaktadır [3]. Toprak verimliliği toprakların birim alandan yüksek verimin alınmasını sağlayan önemli bir parametredir [4]. Bitkisel üretimde hedeflenen kalite ve miktarda ürünün alınması için toprakta bitkiler için gerekli olan yarayışlı bitki besin elementlerinin yeterli bir durumda olması gerekmektedir. Bu amaçla toprakların verimlilik durumlarını

\footnotetext{
*Sorumlu yazar: arozturkmen@harran.edu.tr

Geliş Tarihi: 25.07.2020, Kabul Tarihi: 08.09.2020
} 
belirlemeye yönelik ülkemizde birçok çalışma yapılmıştır. Harran Ovası'nda farklı serilerdeki topraklarda bitkiler için yarayışlı mikro besin elementlerin kapsamlarının belirlendiği çalışmada; çinko $0.16-1.20 \mathrm{mg} / \mathrm{kg}$, demir $2.68-6.40 \mathrm{mg} / \mathrm{kg}$, bakır $0.65-8.18 \mathrm{mg} / \mathrm{kg}$, mangan $2.62-13.05 \mathrm{mg} / \mathrm{kg}$ belirlendiği ve mikro elementlerin ortalama olarak sirasıyla $0.43,4.72,1.60$ ve $6.67 \mathrm{mg} / \mathrm{kg}$ belirlenmiştir. Çalışma sonucunda toprak serilerinde çinko \%80, demir ise $\% 40$ kritik seviyesinin altında olduğunu bildirmişlerdir [5]. Toprakların verimlilik durumlarını değerlendirmek için Şanlıurfa ili Bozova ilçesinde yapılan bir çalışmada mikro besin elementlerinden mangan ve bakır, makro bitki besin elementlerinden ise potasyumun yüksek olduğu bildirilmiştir [6]. Ülkemizin topraklarını temsil edecek şekilde alınan 1511 toprak örneğinde yapılan çalışmada bitkiye yarayışlı mikro besin elementlerinin konsantrasyonları demir 4.5, bakır 0.2 , mangan 1.0 ve çinko ise $0.5 \mathrm{mg} / \mathrm{kg}$ olarak belirlendiği ve ülkemiz topraklarının yarayışlı mikro besin element kapsamları yapılan çalışma sonucunda çinko \%50, demir $\% 27$, mangan $\% 0,7$ sınır değerlerin altında belirlendiğini bildirilmiştir [7]. Harran Ovası topraklarının yarayışlı mikro besin element kapsamlarının belirlendiği çalışmada yüzey topraktan yapılan örnekleme ile çinko $0.80 \mathrm{mg} / \mathrm{kg}$, bakır $4.01 \mathrm{mg} / \mathrm{kg}$, mangan $28.39 \mathrm{mg} / \mathrm{kg}$ ve demir $18.66 \mathrm{mg} / \mathrm{kg}$ olarak tespit edilmiş̧ir [8]. Şanlıurfa ili meyve bahçelerinde yapılan örnekleme çalışması sonucunda toprakların genelinde makro bitki besin elementlerinden azot, mikro bitki besin elementlerinden ise demir ve çinko noksanlığının çok ciddi boyutlarda olduğu belirlenmiş̦tir [9]. Harran Ovası'nda kuru tarım yapılan arazilerde yapılan çalışmada mikro besin elementlerden mangan ve çinko makro besin elementlerinden ise potasyumun yüksek olduğu, toprakların genel olarak killi bünyeli ve organik madde açısından yetersiz olduğu bildirilmiştir [10]. Harran ovasının kuzeyinde yapılan bir çalışmada farklı meyve bahçelerinden alınan toprak örneklerinde yapılan analizler sonucunda toprakların yüksek kireç içeriğe sahip olduğu ve makro besin elementlerinden yarayışlı potasyumun tüm meyve bahçelerinde yüksek olduğu belirlenmiştir [11].

$\mathrm{Bu}$ araştırmanın amacı Şanlıurfa ili Suruç ilçesi topraklarının bazı fiziksel ve kimyasal özelliklerinin belirlenmesi ile birlikte verimlilik durumlarının değerlendirilmesidir.

\section{Materyal ve Metot}

Şanlıurfa ilinde bulunan Suruç Ovası $38^{0} 05^{\prime}$ ve $38^{0} 45^{\prime}$ doğu boylamları ile $37^{0} 05^{\prime}$ ve $37^{0} 45^{\prime}$ kuzey enlemleri arasında yer almaktadır. Ova kuzeyde Karaçi ve Küçükbaş tepeleri, güneyde Suriye sınırı, doğuda Seyit ve Büyükbaş tepeleri ve batıda ise Karadağ ile çevrelenmiştir. Toprak örnekleri Suruç Ovası'nı temsil edecek şekilde Mayıs ayında 70 adet alınmış olup örnekleme noktaları GPS ile koordinatları kaydedilmiştir (Şekil 1). Toprak örnekleri arazide 0-30 cm derinlikten alınmış olup, topraklar daha sonra laboratuvarda analizler için hazır hale getirilmiştir.

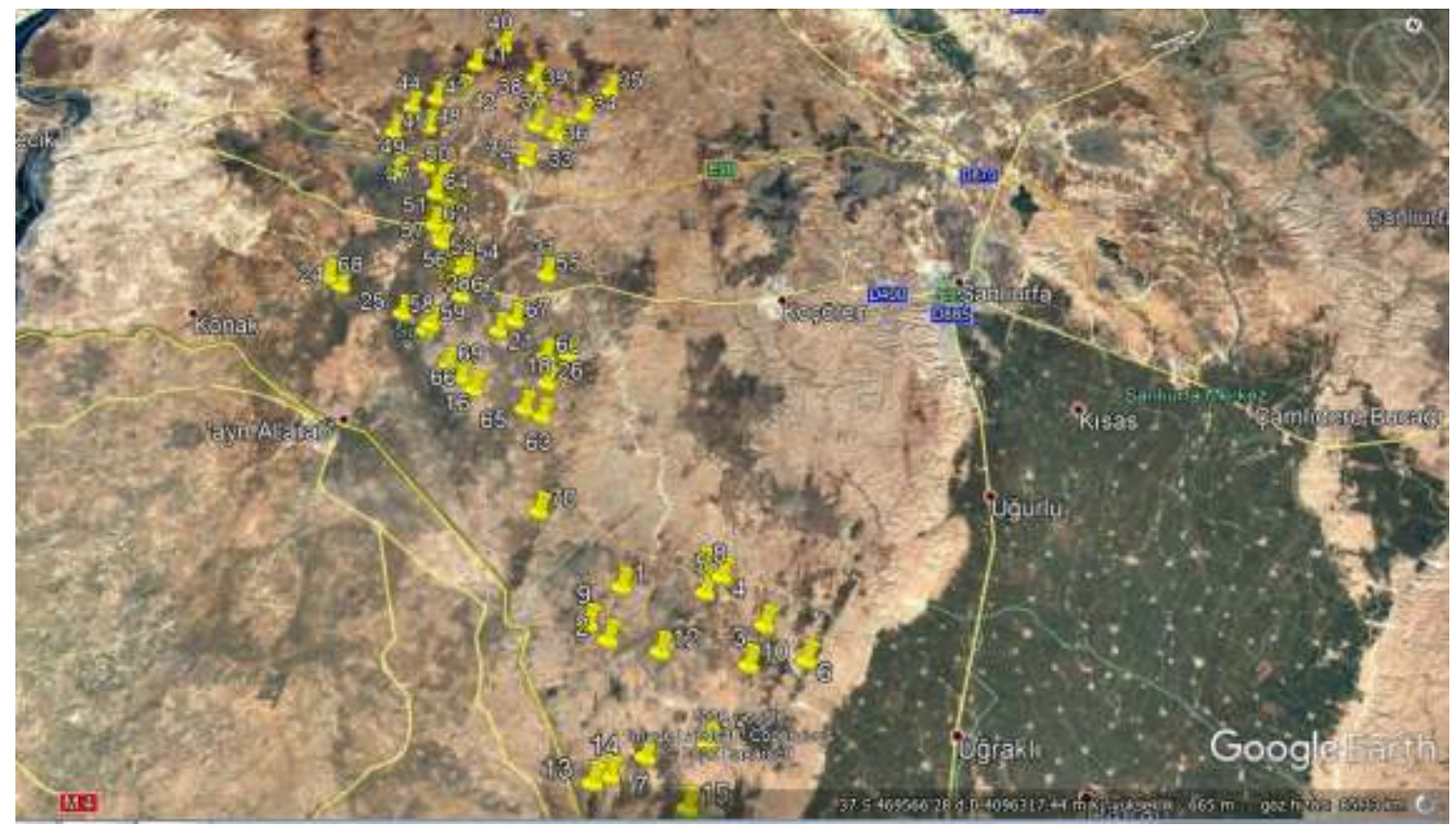

Şekil 1. Toprak örneklerinin alındığı noktalar 
Analizler için hazır hale getirilen toprak örneklerinde bazı fiziksel ve kimyasal analizler yapılmıştır. Saturasyon (\%) [12], toprak reaksiyonu (pH) saturasyon çamurunda [13], kalsiyum karbonat (\%) Scheibler kalsimetresiyle ile [14], toplam tuz (\%) toprak örneklerinin elektriki iletkenlik aletinin çamur hücresine yerleştirilmesiyle belirlenmiştir [15]. Fosfor tayini (Olsen Metodu) $2 \mathrm{~g}$ toprak örneğinin üzerine $40 \mathrm{ml} \mathrm{pH}$ 's1 8.5 ayarlanmış sodyum bikarbonat $\left(\mathrm{NaHCO}_{3}\right)$ solüsyonu ile $30 \mathrm{dk}$ çalkalanma sonucunda UV-VIS spektrofotometresi kullanılarak belirlenmiştir [16]. Organik madde (\%) yaş yakma metodu kullanılarak [17] yapılmıştır. Yarayışlı potasyum tayini 4 gr toprak örneği üzerine pH 7'e ayarlanmış $40 \mathrm{ml} \mathrm{NH} \mathrm{NH}_{4} \mathrm{OAc}(1 \mathrm{~N})$ ekraktsiyon çözeltisinden eklenerek 1 saat süre ile çalkalanmış elde edilen süzükler daha sonra ICP-OES aletinde elementel okumalar gerçekleştirilmiştir [18]. Bitkiye yarayışlı mikro besin elementlerin $(\mathrm{Cu}, \mathrm{Fe}, \mathrm{Mn}$ ve $\mathrm{Zn})$ tayininde 20 gr toprak örneği üzerine $40 \mathrm{ml}$ DTPA ekstrasyon solüsyonu eklenerek 2 saat süre ile çalkalanmıştır. DTPA ekstraksiyon solusyonu $0.005 \mathrm{M}$ DTPA, $0.01 \mathrm{M} \mathrm{CaCl}_{2}$ ve $0.1 \mathrm{M}$ TEA kimyasallarından oluşmaktadır [19]. Bitkiye yarayışlı mikro besin element $(\mathrm{Cu}, \mathrm{Fe}, \mathrm{Mn}$ ve $\mathrm{Zn})$ konsantrasyonları ICP-OES cihazı kullanılarak elementel okumalar gerçekleştirilmiş̧ir.

\section{Bulgular ve Tartışma}

Çalışma alanına ait topraklarda yapılan analizler sonucunda toprakların fiziksel ve kimyasal özelliklerine ilişkin tanımlayıcı istatistikler verilmiştir (Tablo 1). Değişkenlik göstergesi olarak kabul edilen varyasyon katsayıs1 değerleri $\leq \% 15$ küçük, $\% 16-30$ orta, $\% \geq 30$ yüksek değişken olarak sınıflandırılmıştır [20]. Çalışma alanı topraklarının parametreleri incelendiğinde, en az değişkenliği toprak reaksiyonu $(\mathrm{pH})(\mathrm{CV}=0.00)$, toplam tuz $(\mathrm{CV}=0.33)$ ve suya doygunluk $(\mathrm{CV}=11.59)$; yüksek düzeyde değişkenliği ise sırasıyla kireç $(\mathrm{CV}=38.91), \mathrm{Zn}(\mathrm{CV}=43.18)$, organik madde $(\mathrm{CV}=48.18)$, yarayış1 $\mathrm{K}(\mathrm{CV}=49.42), \mathrm{Mn}(\mathrm{CV}=50.95)$, yarayışı $\mathrm{P}(\mathrm{CV}=52.74), \mathrm{Cu}(\mathrm{CV}=53.04)$ ve $\mathrm{Fe}(\mathrm{CV}=75.41)$ göstermiştir. Sonuçlar birçok araştırmacı tarafından yapılan çalışmalarla uyum göstermektedir [20,21]. Suruç Ovası topraklarının yapılan analizler sonucunda oluşan fiziksel ve kimyasal özelliklerine ait tanımlayıcı istatistikler Tablo 1, toprakların bazı fiziksel ve kimyasal özelliklerine göre değerlendirilmesi Tablo 2 ve topraktaki yarayışlı bitki besin elementlerinin değerlendirilmesi Tablo 3 'te verilmiştir.

Tablo 1. Suruç Ovası topraklarının bazı fiziksel ve kimyasal özelliklerine ait tanımlayıcı istatistikler ( $\mathrm{n}=70)$

\begin{tabular}{llcccccc}
\hline Parametreler & Birimler & Max. & Min. & Ort. & V & CV & SD \\
\hline Suya Doygunluk & $\%$ & 74.00 & 44.00 & 58.14 & 45.45 & 11.59 & 6.74 \\
Toplam Tuz & $\%$ & 0.07 & 0.01 & 0.03 & 0.00 & 0.33 & 0.01 \\
Kireç & $\%$ & 66.90 & 3.90 & 29.73 & 133.84 & 38.91 & 11.57 \\
Organik Madde & $\%$ & 2.30 & 0.14 & 1.10 & 0.28 & 48.18 & 0.53 \\
pH & -- & 7.78 & 7.20 & 7.53 & 0.01 & 0.00 & 0.10 \\
Yarayışılı Fosfor & $\mathrm{Kg} \mathrm{P}_{2} \mathrm{O}_{5} \mathrm{da}^{-1}$ & 20.21 & 1.48 & 6.75 & 12.67 & 52.74 & 3.56 \\
Yarayışı Potasyum & $\mathrm{Kg} \mathrm{K}_{2} \mathrm{O} \mathrm{da}^{-1}$ & 453.60 & 16.10 & 159.12 & 6183.90 & 49.42 & 78.64 \\
Demir & $\mathrm{mg} \mathrm{kg}^{-1}$ & 10.86 & 0.53 & 2.40 & 3.29 & 75.41 & 1.81 \\
Bakır & $\mathrm{mg} \mathrm{kg}^{-1}$ & 3.68 & 0.66 & 1.15 & 0.37 & 53.04 & 0.61 \\
Çinko & $\mathrm{mg} \mathrm{kg}^{-1}$ & 1.29 & 0.14 & 0.44 & 0.03 & 43.18 & 0.19 \\
Mangan & $\mathrm{mg} \mathrm{kg}^{-1}$ & 13.44 & 1.07 & 3.65 & 3.44 & 50.95 & 1.86 \\
\hline
\end{tabular}

V: Varyasyon, CV: Varyasyon Katsayısı, SD: standart sapma

Toplam Tuz: Araştırma alanı topraklarının toplam tuz içerikleri 0.07-0.01 dS/m arasında değiştiği ve ortalama olarak 0.03 olduğu belirlenmiştir (Tablo 1). Suruç Ovası topraklarının yapılan analizler sonucunda oluşan frekans tablosuna göre $\% 100$ oranında ovada tuzluluk yönünden herhangi bir sorunun olmadığı ve toprakların tuzsuz olduğu belirlenmiştir [23]. Şanlıurfa ilinde yapılan başka çalışmalarda Harran ve Akçakale ilçelerinin bir kısmı hariç, Şanlıurfa ili topraklarında tuzluluk yönünden bir problemin olmadığını ve her türlü bitki yetiştiriciliğinin yapılabilir durumda olduğu bildirilmiştir $[9,24$, $6,10,25]$. 
Tablo 2. Toprakların bazı fiziksel ve kimyasal özelliklerine göre değerlendirilmesi

\begin{tabular}{|c|c|c|c|c|c|}
\hline Parametreler & Birim & Sınır Değeri & Siniflama & Örnek sayısı & $\%$ \\
\hline \multirow{5}{*}{ Suyla Doygunluk [22] } & \multirow{5}{*}{$\%$} & $<30$ & Kumlu & - & - \\
\hline & & $31-50$ & Tinlı & 7 & 10 \\
\hline & & $51-70$ & Killi-Tınlı & 60 & 86 \\
\hline & & $71-110$ & Killi & 3 & 4 \\
\hline & & $>110$ & Ağır Killi & - & - \\
\hline \multirow{3}{*}{ pH [22] } & \multirow{3}{*}{ - } & $6.5-7.5$ & Nötr & 21 & 30 \\
\hline & & $7.5-8.5$ & Hafif alkali & 49 & 70 \\
\hline & & $>8.5$ & Kuvvetli alkali & - & - \\
\hline \multirow{4}{*}{$\begin{array}{l}\text { Elektriksel İletkenlik (EC) } \\
\text { [12] }\end{array}$} & \multirow{4}{*}{$(\mathrm{dS} / \mathrm{m})$} & $0-4$ & Tuzsuz & 70 & 100 \\
\hline & & $4-8$ & Hafif tuzlu & - & - \\
\hline & & $8-15$ & Orta derece tuzlu & - & - \\
\hline & & $>15$ & Cok fazla tuzlu & - & - \\
\hline \multirow{5}{*}{ Organik Madde } & \multirow{5}{*}{$\%$} & $<1$ & Çok az & 39 & 42 \\
\hline & & $1-2$ & $\mathrm{Az}$ & 36 & 51 \\
\hline & & $2-3$ & Orta & 5 & 7 \\
\hline & & $3-4$ & İyi & - & - \\
\hline & & $>4$ & Yüksek & - & - \\
\hline \multirow{5}{*}{ Kireç } & \multirow{5}{*}{$\%$} & $<1$ & Az kirecli & - & - \\
\hline & & $1-5$ & Kireçli & 1 & 1 \\
\hline & & $5-15$ & Orta & 1 & 1 \\
\hline & & $15-25$ & Fazla & 24 & 33 \\
\hline & & $>25$ & Cok fazla & 46 & 65 \\
\hline
\end{tabular}

Tablo 3. Topraktaki yarayışlı bitki besin elementlerinin değerlendirilmesi

\begin{tabular}{|c|c|c|c|c|c|}
\hline Bitki Besin Elementleri & Birim & Sınır Değerler & Sinıflama & Örnek sayısı & $\%$ \\
\hline \multirow{4}{*}{ Yarayışlı Fosfor } & \multirow{4}{*}{$\mathrm{kg} \mathrm{P} \mathrm{P}_{2} \mathrm{O} 5 \mathrm{da}^{-1}$} & $0-3$ & Çok az & 11 & 17 \\
\hline & & $3-6$ & $\mathrm{Az}$ & 28 & 40 \\
\hline & & $6-9$ & Orta & 19 & 27 \\
\hline & & $9-12$ & Yüksek & 11 & 16 \\
\hline \multirow{4}{*}{ Yarayışlı Potasyum } & \multirow{4}{*}{$\mathrm{kg} \mathrm{K} 2 \mathrm{O} \mathrm{da}{ }^{-1}$} & $<20$ & $\mathrm{Az}$ & 1 & 1 \\
\hline & & $20-30$ & Orta & 0 & 0 \\
\hline & & $30-40$ & Yeterli & 0 & 0 \\
\hline & & $>40$ & Yüksek & 69 & 99 \\
\hline \multirow[b]{2}{*}{ Demir (DTPA) } & \multirow[b]{2}{*}{$\mathrm{mg} \mathrm{kg}^{-1}$} & $<2.5$ & Düşük & 53 & 77 \\
\hline & & $2.5-4.5$ & Orta & 16 & 23 \\
\hline \multirow[b]{2}{*}{ Bakır (DTPA) } & \multirow[b]{2}{*}{$\mathrm{mg} \mathrm{kg}^{-1}$} & $<0.2$ & Yetersiz & - & - \\
\hline & & $>0.2$ & Yeterli & 70 & 100 \\
\hline \multirow{3}{*}{ Çinko (DTPA) } & \multirow{3}{*}{$\mathrm{mg} \mathrm{kg}^{-1}$} & $<0.5$ & Düşük & 47 & 67 \\
\hline & & $0.5-1.0$ & Yeterli & 22 & 31 \\
\hline & & $>1.0$ & Fazla & 1 & 2 \\
\hline \multirow{2}{*}{ Mangan (DTPA) } & \multirow{2}{*}{$\mathrm{mg} \mathrm{kg}^{-1}$} & $<1$ & Yetersiz & - & - \\
\hline & & 1.0 & Yeterli & 70 & 100 \\
\hline
\end{tabular}

Toprak Reaksiyonu (pH): Araştırma alanı toprakları toprak reaksiyonu 7.20-7.78 arasında değişmiş ve ortalama 7.53 olarak belirlenmiştir (Tablo 1). Toprakların nötr ve hafif alkalin olarak belirlendiği ve çalışma alanının genel olarak hafif alkalin olduğu belirlenmiştir (Tablo 2). Çalışma alanı toprakları frekans tablosunda \%30 nötr, \%70 hafif alkalin olduğu görülmektedir (Şekil 3). Benzer sonuçlar birçok araştırmacının sonuçları ile uyum göstermektedir [6, 9, 10, 24, 25]. 


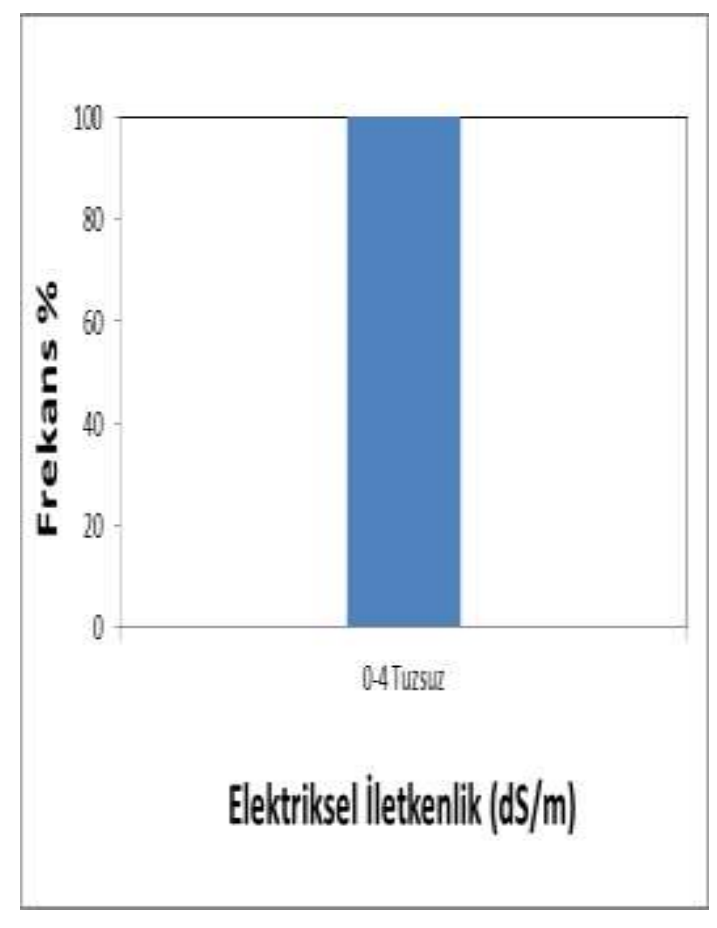

Şekil 2. Alanın \% olarak toplam tuz dağılımı

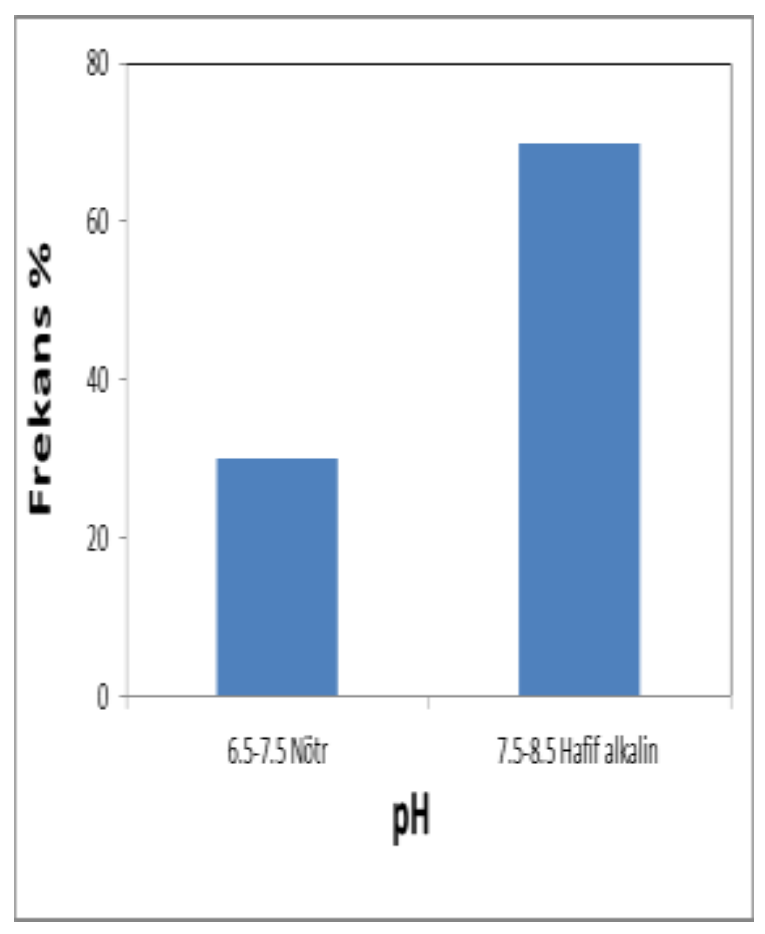

Şekil 3. Alanın toprak reaksiyonu dağılımı

Organik madde: Araştırma alanı topraklarında organik madde \% 0.14-2.30 arasında değişmekte olup, ortalama 1.10 olarak belirlenmiştir (Tablo 1). Organik maddenin araştırma alanında genel olarak az olduğu (Tablo 2), ve toprakların organik madde oranı $\% 42$ çok az, $\% 51$ az ve $\% 7$ orta olarak belirlenmiştir (Şekil 4). Çalışma alanının organik madde seviyesinin oldukça düşük olması daha önce yapılan birçok çalışma ile uyum göstermektedir [6, 9, 10, 24, 25].

Kireç: Araştırma alanı topraklarında yapılan toplam kireç analizi sonucunda toprakların kireç içerikleri \%3.90-66.90 arasında değişmekte olup, ortalama \%29.73 olduğu belirlenmiştir (Tablo 1). Toprakların genel olarak çok yüksek kireç içeriğine sahip oldukları saptanmıştır (Tablo 2). Araştırma alanı topraklarında toplam kireç dağılımları ise $\% 1$ az kireçli, $\% 1$ orta, $\% 33$ fazla ve $\% 65$ çok yüksek kireç içeriğine sahip olduğu tespit edilmiş olup (Şekil 5), bu sonuçlar birçok araştırmacının yapmış olduğu çalışmalarla uyum göstermektedir $[6,9,10,24,25]$. Araştırma alanından alınan toprak örneklerindeki yüksek kireç içeriği toprakların üzerinde oluştuğu ana materyalden kaynaklanmaktadır. Suruç Ovası kireçli ana materyal üzerinde oluşmuş topraklardır.

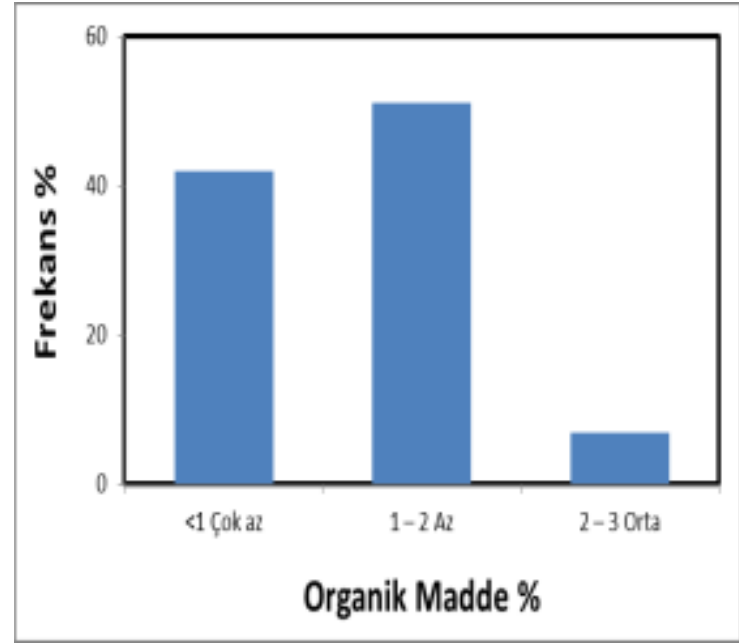

Şekil 4. Alanın \% organik madde dağılımı

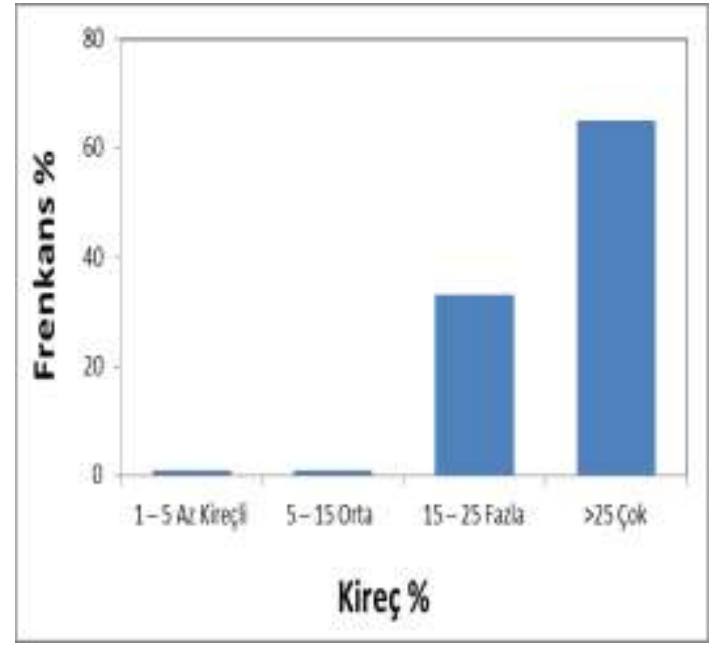

Şekil 5. Alanın \% kireç dağılımı 
Yarayışlı Fosfor: Araştırma alanı topraklarında yapılan fosfor tayini sonucunda toprakların yarayışlı fosfor içerikleri 1.48-20.21 Kg $\mathrm{P}_{2} \mathrm{O}_{5} \mathrm{da}^{-1}$ arasında değiştiği ve ortalama $6.75 \mathrm{Kg} \mathrm{P}_{2} \mathrm{O}_{5} \mathrm{da}^{-1}$ olarak belirlenmiştir (Tablo 1). Araştırma alanı fosfor bakımından orta düzeydedir (Tablo 3). Araştırma alanı topraklarında fosfor dağılımı genel olarak \%17 çok az, \%40 az, \%27 orta ve \%16 yüksek olarak tespit edilmiştir (Şekil 6). Toprakların fosfor içeriklerindeki farklılık tarım yapılan arazilerde çiftçilerin farklı miktarlarda fosfor içerikli gübreleri kullanmasından kaynaklandığı ve fosfor bakımından bulunan sonuçların daha önce yapılan birçok çalışma ile uyum gösterdiği görülmüştür.

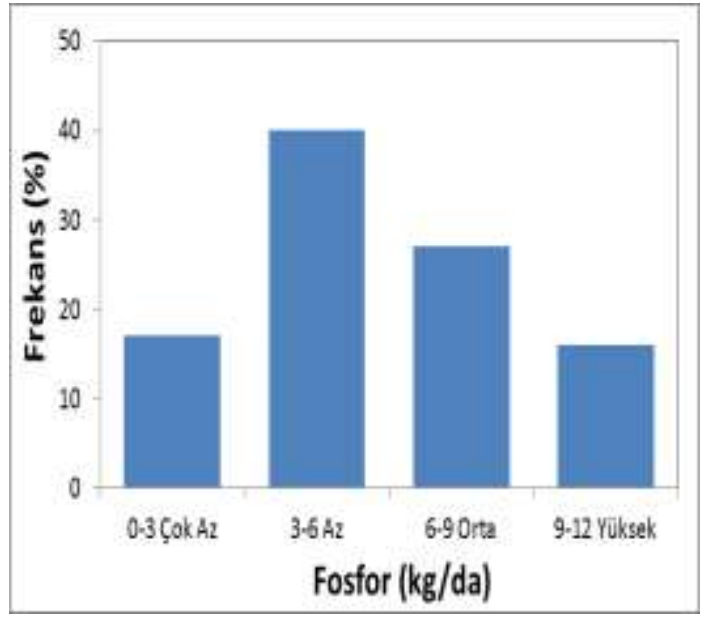

Şekil 6. Araştırma alanının \% olarak fosfor dağılımı

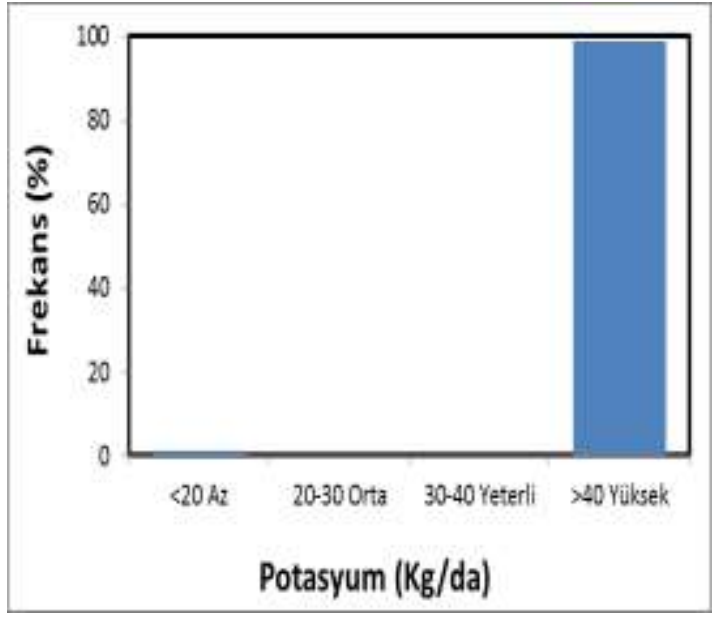

Şekil 7. Araştırma alanının \% potasyum dağılımı

Yarayış̧ı Potasyum: Araştırma alanı topraklarında bitkiye yarayışlı potasyum miktarları 16.10-453.60 $\mathrm{Kg} \mathrm{K}_{2} \mathrm{O}$ da ${ }^{-1}$ arasında değişmekle birlikte, ortalama $159.12 \mathrm{Kg} \mathrm{K}_{2} \mathrm{O}$ da ${ }^{-1}$ olarak belirlenmiştir (Tablo 1). Araştırma alanı toprakları genel olarak yarayışlı potasyum konsantrasyonu bakımından yüksek olduğu (Tablo 3), araştırma alanındaki dağılım ise \%1 az, \%99 yüksek olarak saptanmıştır (Şekil 7). Potasyum bitkilerde genellikle meyve kalitesi üzerine bir çok olumlu etkisi vardır. Bu nedenle topraklarda yarayışlı potasyumun düzenli olarak kontrol edilip, gerektiğinde gübreleme yapılmalıdır. Araştırma alanı ile ilgili bulunan sonuçlar birçok araştırmacının sonuçlarıyla uyum göstermektedir $[6,9,10,24,25]$.

Demir: Araştırma alanı topraklarında bitkiye yarayışlı demir konsantrasyonu $0.53-10,86 \mathrm{mg} \mathrm{kg}^{-1}$ arasında değiştiği ve ortalama $2.40 \mathrm{mg} \mathrm{kg}^{-1}$ olduğu belirlenmiştir (Tablo 1). Araştırma alanı topraklarında demir konsantrasyonunun düşük olduğu gözlenmiştir (Tablo 3) [19]. Araştırma alanı demir konsantrasyonu dağılımının \%77 düşük ve \%23 orta düzeyde olduğu tespit edilmiştir (Şekil 8). Araştırma sonuçları başka araştırmacıların yapmış olduğu çalışmalarla benzerlik göstermektedir [25].

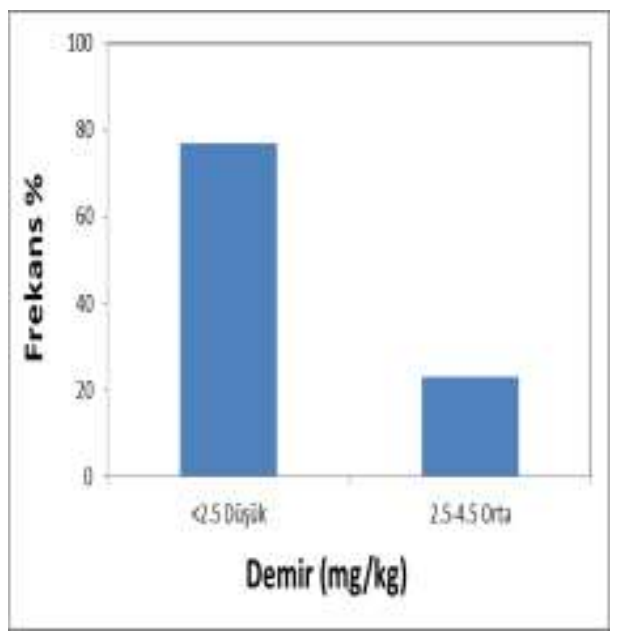

Şekil 8. Alanın \% olarak demir dağılımı

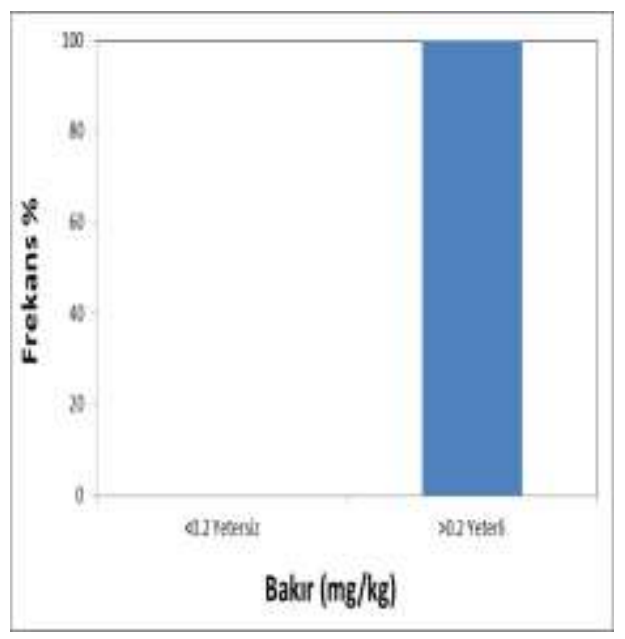

Şekil 9. Alanın \% olarak bakır dağılımı 
Bakır: Araştırma alanı topraklarında bitkiye yarayışı bakır konsantrasyonu 0.66-3.68 mg kg ${ }^{-1}$ arasında değişmekte olup, ortalama $1.15 \mathrm{mg} \mathrm{kg}^{-1}$ olarak saptanmıştır (Tablo 1). Araştırma alanı toprakları bakır konsantrasyonu açısında yeterli olduğu belirlenmiştir (Tablo 3) [19]. Araştırma alanında demir konsantrasyonu dağılımı ise \%100 oranında yeterli bulunmuştur (Şekil 9). Araştırma sonucu başka araştırmacılar tarafindan yapılan çalışmalarla benzerlik göstermektedir [25].

Çinko: Araştırma alanı topraklarında bitkiye yarayışlı çinko konsantrasyonu $0.14-1.29 \mathrm{mg} \mathrm{kg}^{-1}$ arasında değişmekte olup, ortalama $0,44 \mathrm{mg} \mathrm{kg}^{-1}$ olarak belirlenmiştir (Tablo 1). Araştırma alanı toprakları çinko konsantrasyonu açısında düşük olduğu saptanmıştır (Şekil 10) [19]. Araştırma alanı çinko konsantrasyonu dağ 1 lımı ise $\% 67$ düşük, \%31 yeterli ve $\% 2$ yüksek olarak bulunmuştur. Başka araştırmacılar tarafindan da yapılan çalışmalarda çinko yetersiz bulunmuştur [9, 25].

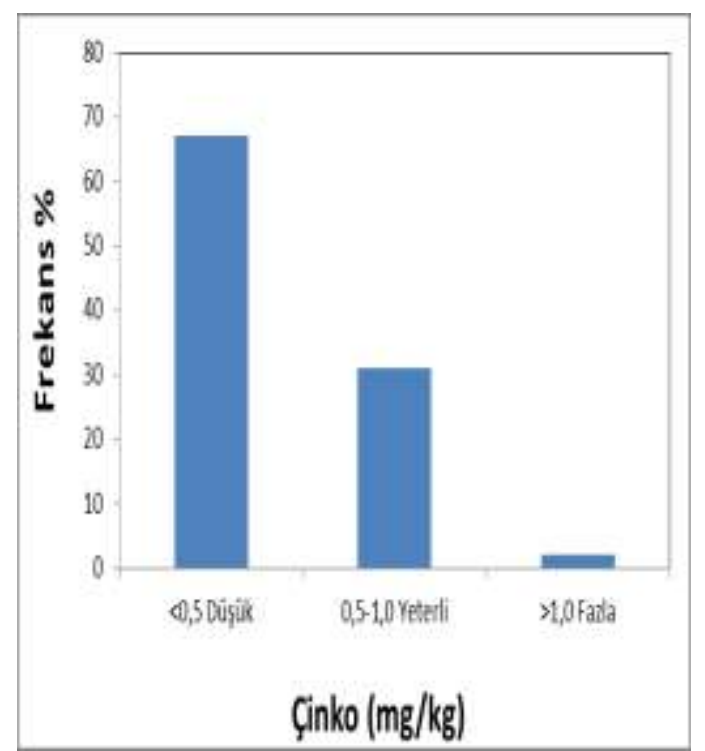

Şekil 10. Alanın \% olarak Çinko dağılımı

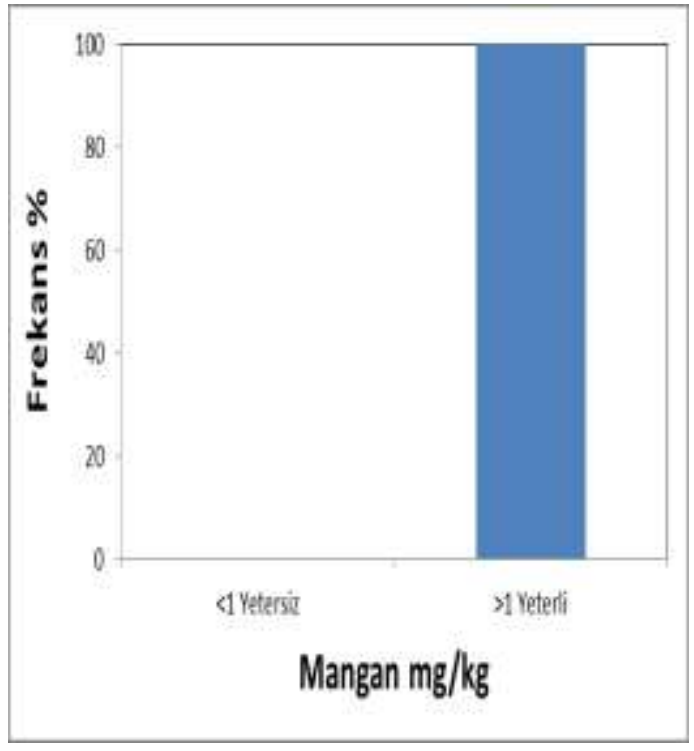

Şekil 11. Alanın \% olarak Mangan dağılımı

Mangan: Araştırma alanı topraklarında bitkiye yarayışlı mangan konsantrasyonu $1.07-13.44 \mathrm{mg} \mathrm{kg}^{-1}$ arasında değişmekte olup, ortalama $3.65 \mathrm{mg} \mathrm{kg}^{-1}$ olarak belirlenmiştir (Tablo 1). Araştırma alanı toprakları mangan konsantrasyonu açısından yeterli olduğu gözlenmiştir (Tablo 3) [19]. Araştırma alanı mangan konsantrasyonu dağılımı ise \%100 oranında yeterli bulunmuştur (Şekil 11). Başka araştırmacılar tarafindan da yapılan çalışmalarda mangan yeterli bulunmuştur [25, 26].

\section{Sonuç ve Öneriler}

Şanlıurfa ili Suruç ilçesinde tarımsal üretimin yapıldığ 1 alanlarda yürütülen çalışmada 70 adet 0-30 derinliğinden alınan toprak örneklerinde yapılan analizlere göre Suruç Ovası topraklarının toprak reaksiyonu yönünde hafif alkalin reaksiyon, toprakların toplam tuz içeriğine göre tuzsuz, organik madde yönünden az ve kalsiyum karbonat içeriği yüksek olarak belirlenmiştir. Kireçli ana materyal üzerinde oluşmuş topraklar olduğundan toprakların alınabilir fosfor içeriği yönünden az olduğu, yarayışlı potasyum içeriği yönünden yüksek olduğu tespit edilmiştir. Bitkiye yarayışlı mikro besin elementi içerikleri bakımından bakırın yeterli, çinkonun yetersiz, manganın yeterli ve demirin düşük olduğu gözlenmiştir.

Suruç Ovası geniş tarım arazilerinin olduğu ve yoğun tarım yapılan Şanlıurfa ilinde yer alan ovalardan biridir. Bu çalışma Şanlıurfa ili Suruç ilçesi topraklarının özellikleri ve toprak verimlilik durumlarının değerlendirilmesi amacıyla yapılmıştır. Elde edilen veriler sulama sonrası ovada meydana gelebilecek değişiklikleri ortaya koyacak ve ovada sulama sonrası yapılacak çalışmalara yön verecektir. 


\section{Teşekkür}

Bu çalışma, Harran Üniversitesi Bilimsel Araştırmalar Koordinasyon Birimi tarafından desteklenmiştir (Proje No: 15048).

\section{Yazarların Katkısı}

$\mathrm{Bu}$ makaledeki değerlendirme ve grafik tasarımları Emrah RAMAZANOGLU tarafından yapılmıştır. Makale Ali Rıza ÖZTÜRKMEN ve İsmail Cihan ÇİÇEK tarafından yazılmıştır.

\section{Çıkar Çatışması Beyanı}

Yazarlar arasında herhangi bir çıkar çatışması bulunmamaktadır.

\section{Araştırma ve Yayın Etiği Beyanı}

Yapılan çalışmada araştırma ve yayın etiğine uyulmuştur.

\section{Kaynaklar}

[1] Alabi A.A., Adewale A.O., Adebo B., Ogungbe A.S., Coker J.O., Akinboro F.G., Bolaji G. 2019. Effects of different land uses on soil physical and chemical properties in Odeda LGA, Ogun State, Nigeria. Environ Earth Sci., 78: 207.

[2] Nassar M., Levy R., Noel Keough N., Nassar N. 2017. Agricultural Land Use Change and its Drivers in the Palestinian Landscape Under Political Instability, the Case of Tulkarm City. Journal of Borderlands Studies, 34 (2):1-18.

[3] Kabir B.E., Bashari H., Bassiri M., Mosaddeghi R.M. 2020. Effects of land-use/cover change on soil hydraulic properties and pore characteristics in a semi-arid region of central Iran. Soil\&Tillage Research, 197: 104478.

[4] Nath J.A., Lal R. 2017. Effects of Tillage Practices and Land Use Management on Soil Aggregates and Soil Organic Carbon in the North Appalachian Region. USA.Pedosphere, 27 (1): 172-176.

[5] Güzel N., Ortaş İ., İbrikçi H. 1991. Harran Ovası Toprak Serilerinde Yararlı Mikroelement Düzeyleri ve Çinko Uygulamasına Karşı Bitkinin Yanıtı. Çukurova Üniv. Zir. Fak. Dergisi, 6 (1): 15-30.

[6] Saraçoğlu M., Taş M., Koşar İ., Yetim S., Sürücü A. 2009. Şanlıurfa İli Bozova İlçesi Topraklarının Bitki Besin Elementi Kapsamlarının Belirlenmesi. IX. Ulusal Ekoloji ve Çevre Kongresi, 7-10 Ekim 2009, Nevşehir.

[7] Eyüpoğlu F., Kurucu N., Talaz S. 1995. Türkiye Topraklarının Bitkiye Yarayışlı Bazı Mikro elementler ( $\mathrm{Fe}, \mathrm{Cu}, \mathrm{Zn}, \mathrm{Mn}$ ) Bakımından Genel Durumu. Toprak ve Su kaynakları Araştırma Yıllığ1, Yayın No: 98, 1996, Ankara.

[8] Kızılgöz İ., Kızılkaya R., Kaptan H., Sürücü A. 1998. Harran Ovas1 yaygın toprak serilerinin DTPA ile ekstrakte edilebilir mikroelement içerikleri ve bazı toprak özellikleriyle ilişkileri. Harran Üniversitesi Ziraat Fakültesi Dergisi, 2 (4): 27-34.

[9] Kızılgöz İ., Kızılkaya R., Açar İ., Seyrek A., Kaptan H. 1999. Şanlıurfa Yöresinde antepfistığ1 (Pistacia vera L.) yetiştirilen toprakların verimlilik düzeylerinin saptanması üzerine bir araştırma. GAP I. Tarım Kongresi, 26-28 Mayıs, II: 987-994, Şanlıurfa.

[10] Saraçoğlu M., Polat H., Anlağan Taş M., Koşar İ., Yetim S., Sürücü A. 2010. Şanlıurfa İli Harran İlçesi Kuru Alanlardaki Toprakların Bitki Besin Elementi Kapsamlarının Belirlenmesi. I. Ulusal Toprak ve Su Kongresi, 1-4 Haziran, Toprak ve Su Kaynakları Araştırma Enstitüsü Müdürlügü, Eskişehir.

[11] Ramazanoglu E. 2019. Determination and Mapping of the Relationship between Potassium and Ammonium of Calcareous Soils with Different Moisture Content. International Journal of Scientific and Technological Research, 5 (7): 17-26. 
[12] Richards L.A. 1954. Diagnosis and Improvement Saline and Alkaline Soils. U.S. Dep. Agr. Handbook 60.

[13] Black C.A. 1965. Methods of Analysis Agreon. No: 9, Ame. Soc. Agr., Madison Wisconsin, USA.

[14] Gülçur F. 1974. Toprağın Fiziksel ve Kimyasal Analiz Metodları. İstanbul Üniversitesi Orman Fakültesi Yayınları, İ.Ü. Yayın No: 1970, Yayın No: 201, Kurtulmuş Matbaası, İstanbul.

[15] Jackson M.C. 1962. Soil chemical analysis. Prentice Hall. Inc. Eng., Cliff, USA.

[16] Kuo S. 1996. Phosphorus in D.L. Sparks (Ed) Methods of Soil Analysis, Part 3, Chemical Methods, SSSA Book Series Number 5, SSSA., Madison, WI, 869-921.

[17] Walkley A., Black I.A. 1934. An examination of the Degtjareff method for determining organic carbon in soils: Effect of variations in digestion conditions and of inorganic soil constituents. Soil Sci., 63: 251-263.

[18] Helmke P.A., Sparks D.L. 1996. Lithium, Sodium, Potassium, Rubidium, and Calciu,in Sparks. D.L., (Ed) Methods of Soil Analysis, Part 3, Chemical Methods, SSSA Book Series Number 5, SSSA., Madison, WI, 551-574.

[19] Lindsay W.L., Norvel W.A. 1978. Development of DTPA soil test for Zn, Fe, Mn and Cu. Soil Sci. Amer. J., 42 (3): 421-428.

[20] Wilding L.P., Bouma J., Gross D.W. 1994. Impact of spatial variability on interpretative modelling, In: Quantitative Modelling of Soil Forming Processes R.B. Bryant and Arnold R.W. (ed), SSSA Special Publication Number 39, SSSA, Inc. Madison Wisconsin, USA

[21] Akbas F., Durak A. 2006. Entisol ordosuna ait bir arazide bazı toprak özelliklerinin değişiminin belirlenmesi. Selçuk Üniversitesi Ziraat Fakültesi Dergisi, 20 (39): 43-52.

[22] Ülgen N., Yurtsever N. 1995. Türkiye Gübre ve Gübreleme Rehberi. 4. Bask1, T.C. Başbakanlık Köy Hizmetleri Genel Müdürlügü Toprak ve Gübre Araştırma Enstitüsü Müdürlüğü Yayınları, Genel Yayın No: 209, Teknik Yayınlar No: T.66, Ankara, 1-230.

[23] Tüzüner A. 1990. Toprak ve Su Analiz Laboratuarları El Kitabı. Köy Hizmetleri Genel Müdürlügü Yayınları, Ankara.

[24] Seyrek A., Kızılgöz İ., Çullu M.A., İnce F. 1999. Harran Ovasında Taban Suyu Etkisindeki Toprakların Ağır Metal İçerikleri. GAP 1. Tarım Kongresi, 26-28 Mayıs, Şanlıurfa.

[25] Saraçoğlu M., Anlağan Taş M., Koşar İ., Aydoğdu M., Kara H., Sürücü A., Oğur Özkan N. 2013. Şanlıurfa İli Hilvan İlçesi Kuru Alanlardaki Toprakların Bitki Besin Elementi Kapsamlarının Belirlenmesi. 6.Ulusal Bitki Besleme ve Gübreleme Kongresi, 3-7 Haziran, Toprak Gübre ve Su Kaynakları Merkez Araştırma Enstitüsü Müdürlüğü, Nevşehir.

[26] Bayraklı F., Gezgin S. 1996. Kanalizasyon suyu ile sulanan tarım topraklarında kirlenme durumu. İstanbul Büyükşehir Belediyesi Org. Bildiri. İstanbul. 